\title{
Lymphangioma of popliteal fossa masquerading as Baker's cyst
}

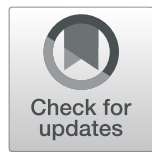

Elamparidhi Padmanaban ${ }^{1 *}$ (D), Sanika Suryawanshi', Umamageswari Amirthalingam', Thara Keloth ${ }^{2}$ and Rintu George ${ }^{1}$

\begin{abstract}
Background: Lymphatic malformations are the second most common vascular malformations after venous malformations. These slow-flow lesions occur most often in the paediatric population and seldom in the extremities. We report a case of lymphangioma at the popliteal fossa in an adult who underwent complete surgical resection.

Case presentation: A 30-year-old male presented to the department of orthopaedics with a swelling in the right calf region. Clinically, it was suspected to be a Baker's cyst. Ultrasound showed a multiloculated anechoic cystic lesion in the inferior aspect of popliteal fossa along the intermuscular plane with multiple internal septations. Infected Baker's cyst was considered, and MRI was suggested for further evaluation. On MRI, the lesion measured $7.2 \times 4.6 \times 5.8 \mathrm{~cm}$, appeared as a low signal on T1 and high signal on STIR and T2, with multiple internal septations and was situated in the inferior aspect of the right popliteal fossa along the intermuscular plane between the lateral head of gastrocnemius and soleus muscles. No obvious synovial extension. A post-contrast study showed minimal peripheral and septal enhancement. Neither internal enhancing solid components nor significant internal derangement of the knee was observed. Diagnosis of lymphangioma was considered based on the imaging features and ruling out the common differentials for cystic lesions around the knee. Wide local excision was performed. Histopathological evaluation showed multiple irregularly dilated lymphatic channels lined by flatted epithelium. The lymphatic channels were seen to be surrounded by thick fibro collagenous cyst wall with scattered congested blood vessels, skeletal muscle fibre and chronic inflammatory cells.
\end{abstract}

Conclusion: Lymphangioma must be included in the differential diagnosis of any cystic lesion if the lesion appears multiseptated and/or infiltrative. At the popliteal fossa, it presents as a multiseptated cyst with no synovial continuity or internal derangement of the knee.

Keywords: Lymphangioma, Popliteal fossa, Baker's cyst, Cystic hygroma, Lymphatic malformation

\footnotetext{
* Correspondence: pepsantosh@gmail.com

'Department of Radiodiagnosis, Sri Manakula Vinayagar Medical College and Hospital, Puducherry, India

Full list of author information is available at the end of the article
}

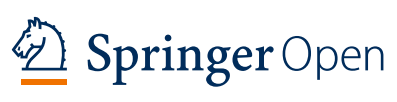

(c) The Author(s). 2021 Open Access This article is licensed under a Creative Commons Attribution 4.0 International License, which permits use, sharing, adaptation, distribution and reproduction in any medium or format, as long as you give appropriate credit to the original author(s) and the source, provide a link to the Creative Commons licence, and indicate if changes were made. The images or other third party material in this article are included in the article's Creative Commons licence, unless indicated otherwise in a credit line to the material. If material is not included in the article's Creative Commons licence and your intended use is not permitted by statutory regulation or exceeds the permitted use, you will need to obtain permission directly from the copyright holder. To view a copy of this licence, visit http://creativecommons.org/licenses/by/4.0/. 


\section{Background}

Lymphatic malformations are the second most common vascular malformations after venous malformations. Lymphatic malformations are commonly known as cystic hygromas or lymphangiomas. These slow-flow lesions occur most often in the paediatric population and seldom in the extremities. It tends to occur predominantly in the neck and axilla. Diagnosis must be considered in cases of multiseptated cysts. Lymphangiomas generally do not show significant post-contrast enhancement. Post-contrast enhancement can be seen in mixed types like veno-lymphatic malformations. These lesions tend to infiltrate into the surrounding tissues rather than displacing them. We report a case of lymphangioma at the popliteal fossa in an adult who underwent complete surgical resection.

\section{Case presentation}

A 30-year-old male presented to the department of orthopaedics with a swelling in the right calf region for 2 years, which was painful for a month (Figs. 1, 2, 3, 4, 5, and 6). Clinically, it was suspected to be an infected Baker's cyst and was referred for radiological evaluation.

On ultrasound, a multiloculated anechoic cystic lesion was noted in the inferior aspect of the popliteal fossa along the intermuscular plane with multiple internal septations. No significant internal vascularity was noted. Minimal internal echoes were seen within. Infected Baker's cyst was considered and MRI was suggested for further evaluation.

On MRI, the lesion measured $7.2 \times 4.6 \times 5.8 \mathrm{~cm}$, appeared as a low signal on $\mathrm{T} 1$ and high signal on
STIR and T2. It was well defined with multiple internal septations and was situated in the inferior aspect of the right popliteal fossa along the intermuscular plane between the lateral head of gastrocnemius and soleus muscles, with no obvious synovial extension. No adjacent inflammatory changes were present. The lesion showed minimal peripheral and septal enhancement on the post-contrast study. No enhancing solid components or internal derangement of the knee was observed. Diagnosis of lymphangioma was considered based on the imaging features and ruling out the common differentials for cystic lesions around the knee.

Wide local excision was performed. Intra-operatively, the lesion appeared to be a pearly white wellencapsulated cyst in the intermuscular plane. It was separate from the neurovascular bundle and had no continuity with the joint.

Histopathological evaluation showed multiple irregularly dilated lymphatic channels lined by flatted epithelium. The lymphatic channels were seen to be surrounded by thick fibro collagenous cyst wall with scattered congested blood vessels, skeletal muscle fibre and chronic inflammatory cells.

\section{Discussion}

Lymphatic malformations are the second most common malformations after venous malformations [1]. Lymphatic malformations are commonly known as cystic hygromas or lymphangiomas. These slow-flow lesions occur most often in the paediatric population and seldom in the extremities [2]. Common cystic

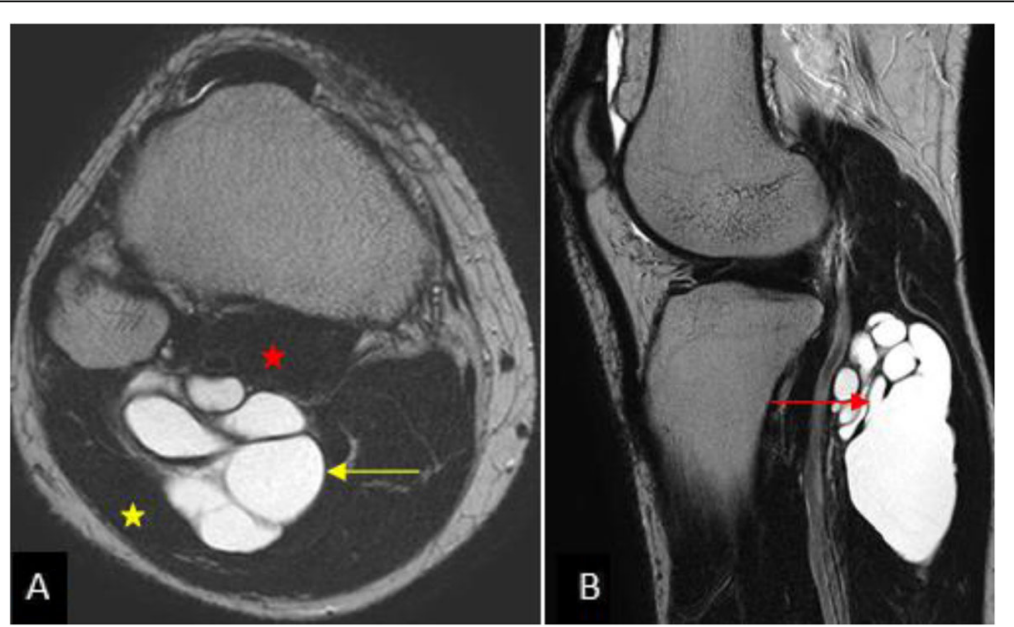

Fig. 1 Thirty-year-old male with lymphangioma in the proximal leg along the posterior aspect. Findings: axial (a) and sagittal (b) T2WI images at the level of the proximal leg showing a multiloculated high-signal intensity lesion in the intermuscular plane between the soleus (yellow arrow) and lateral head of the gastrocnemius muscles (yellow asterisk). Multiple thin internal septations seen within predominantly in the superior aspect (red arrow). The lesion appears to be away from the joint with no intra-articular continuation. Technique: Philips Insta 1.5-T MRI-T2WI axial and sagittal: TR 4843 ms, TE $100 \mathrm{~ms}$, matrix $324 \times 260$ and slice thickness $3 \mathrm{~mm}$ 

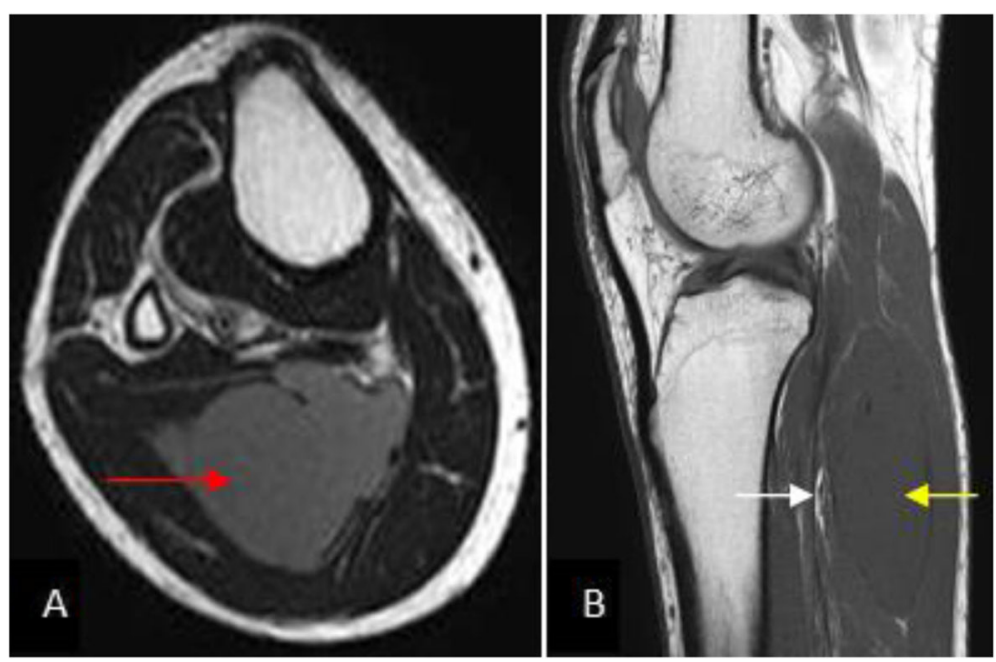

Fig. 2 Thirty-year-old male with lymphangioma in the proximal leg along the posterior aspect. Findings: FLAIR axial (a) and T1WI sagittal (b) images showing the lesion in the intermuscular plane which appears as a low signal on T1WI (yellow arrow) and shows homogenous suppression on FLAIR (red arrow). Fat plane is maintained with the adjacent muscles (white arrow). Technique: Philips Insta 1.5-T MRI—FLAIR axial: TR 11,000 ms, TE 120 ms, TI 2800 ms, matrix $256 \times 144$ and slice thickness 3 mm; T1Wl axial: TR 522 ms, TE 18 ms, matrix $380 \times 258$ and slice thickness $3 \mathrm{~mm}$

lesions in and around the popliteal fossa are meniscal cyst, synovial cyst (Baker's cyst) and ganglionic cyst. Lymphangioma at popliteal fossa has been rarely reported [3]. The most common types of vascular malformations are venous, lymphatic and venolymphatic with an overall prevalence of up to $1 \%$ in

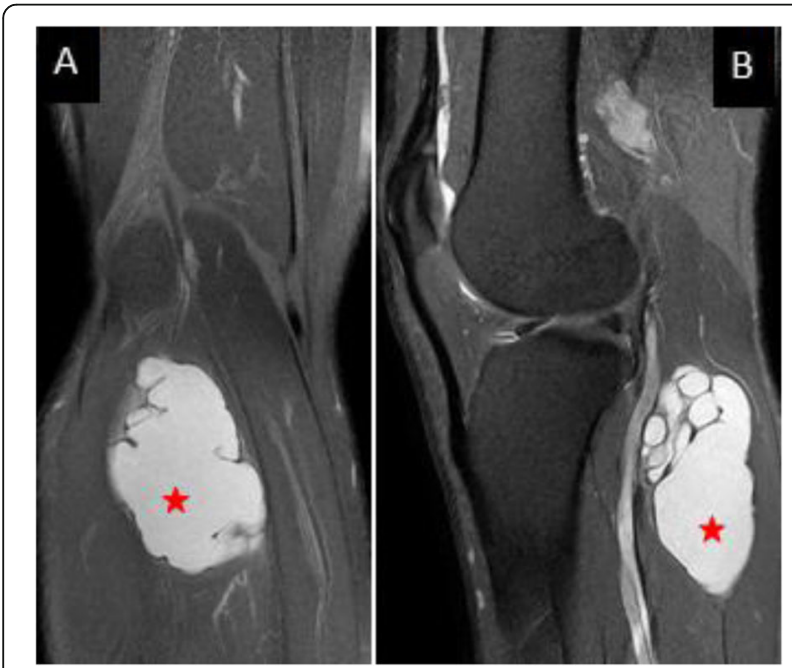

Fig. 3 Thirty-year-old male with lymphangioma in the proximal leg along the posterior aspect. Findings: coronal (a) and sagittal (b) STIR images. The lesion shows a high signal (red asterisk). Adjacent muscle show normal signal, suggestive of a lack of perilesional inflammation. Technique: Philips Insta 1.5-T MRI—STIR coronal and sagittal: TR 3762 ms, TE 80 ms, TI 150 ms, matrix $240 \times 168$ and slice thickness $3 \mathrm{~mm}$ the general population [4]. Lymphangioma may involve almost every organ system, soft-tissue lymphatic malformations most commonly occurring in cervicofacial (up to $75 \%$ of cases), axillary (up to $25 \%)$, or mediastinal (3-10\%) areas [2]. Approximately $95 \%$ of lymphangiomas are found in the neck and axilla, and the other $5 \%$ occur in the mediastinum and abdominal cavity, including the mesentery, retroperitoneum and bones [5]. The aetiology of lymphangiomas is still unclear. They are considered to be congenital dysplasia of lymphatic tissue and abnormal development of the lymphatic vessels during foetal life $[6,7]$.

The occurrence of lymphangiomas in the upper and lower limbs has been published in a few case reports [8]. Males and females are equally affected. Generally, the presentation of the lymphangiomas may be with symptoms related to the local effect or painless swelling. A clinical examination may reveal soft non-tender masses on palpation with a doughy consistency.

On ultrasound, lymphangioma appears as a multilocular anechoic cystic mass with internal septa of varying thickness located in the intermuscular plane. The appearance of the cyst is variable depending on the presence or absence of secondary infection. Wide variations exist such as cystic mass with solid areas or mostly solid with cystic foci.

Most of the lymphangiomas appear homogenous on CT scan, but some appear inhomogeneous due to the presence of the proteinaceous, fluid, blood or 

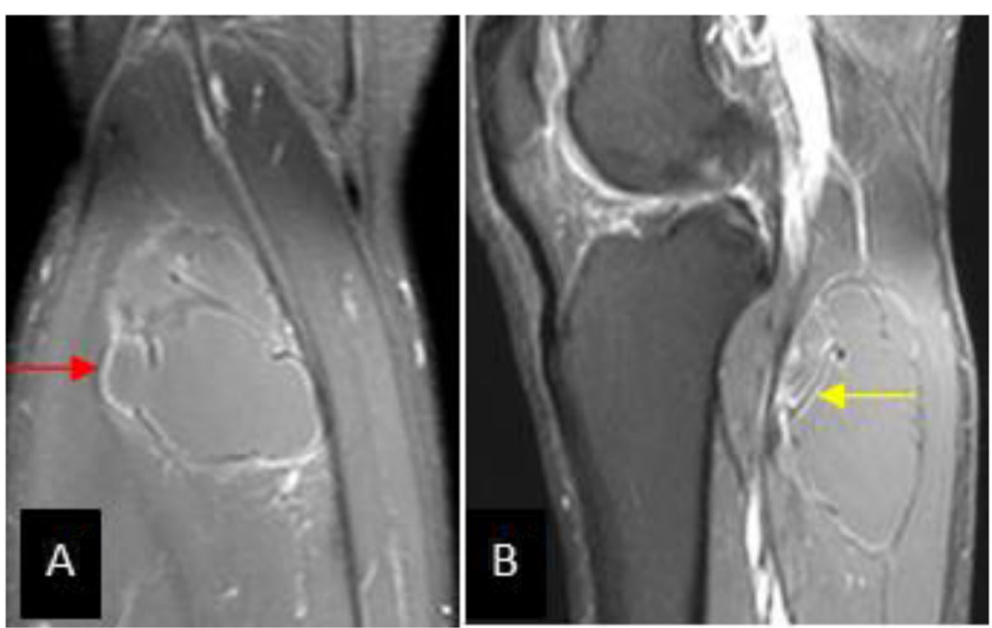

Fig. 4 Thirty-year-old male with lymphangioma in the proximal leg along the posterior aspect. Findings: coronal (a) and sagittal (b) post-contrast fat saturation images showing enhancing capsule (red arrow) and internal septae (yellow arrow). No enhancing mural components/papillary projections are seen within. No enhancement is seen in the adjacent muscles. Technique: Philips Insta 1.5-T MRI—fat-saturated, post-Gd T1WI: TR $522 \mathrm{~ms}$, TE $18 \mathrm{~ms}$, matrix $380 \times 258$ and slice thickness $3 \mathrm{~mm}$ (contrast used_diamagnetic contrast—gadobutrol $10 \mathrm{ml}$ )

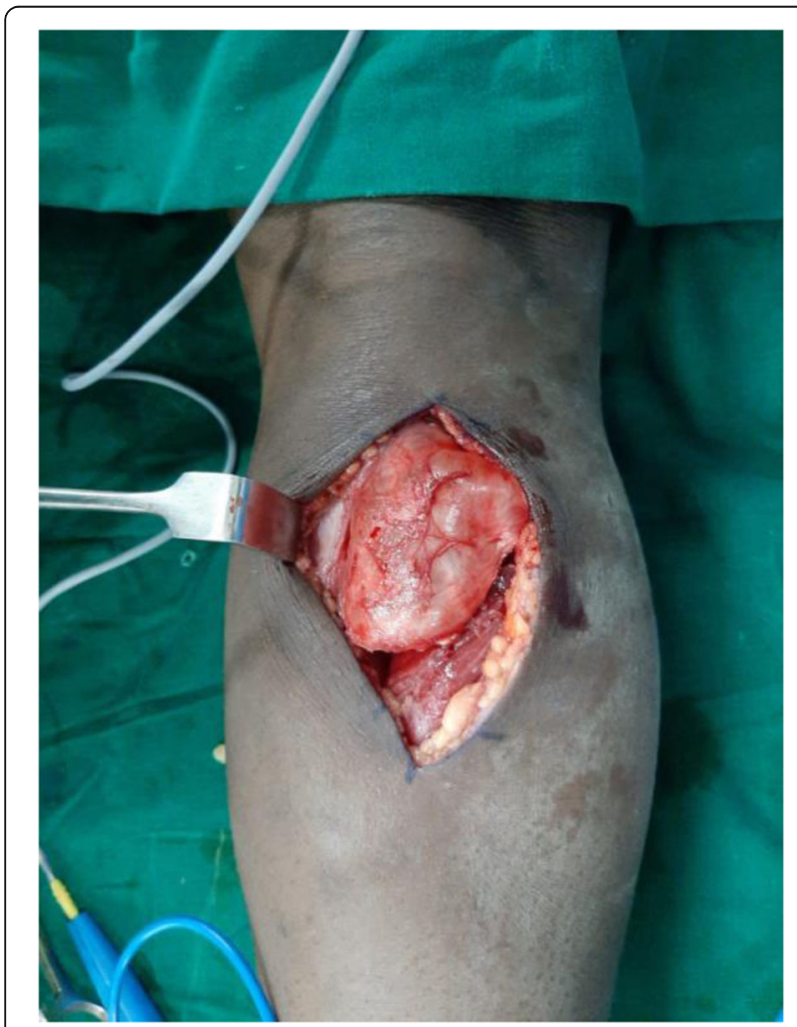

Fig. 5 Intraoperative image showing a pearly white wellencapsulated cystic lesion in the intermuscular plane. The lesion was separated from the neurovascular bundle and had no continuity with the joint fat components. Minimal displacement or compression of the adjacent structures might be seen.

On MR imaging, lymphatic malformations appear as multiseptated cystic masses that can infiltrate surrounding tissues, sometimes causing hypertrophy of the affected body part. The cysts are typically hypointense on T1-weighted images and hyperintense on T2-weighted images [2]. More heterogeneous signal intensity may be seen within cysts with proteinaceous or haemorrhagic content. The cysts do not characteristically enhance, although the septa, which are vascularised, show contrast material uptake. There may also be enhancement of the venous component in mixed malformations. In the microcystic form, the cysts may not be visible as distinct elements, and the lesion may appear slightly hyperintense after gadolinium administration due to septal enhancement [2].

The two main strategies used to treat lymphatic anomalies are sclerotherapy and surgical resection. Sclerotherapy works through the obliteration of the lymphatic lumen [9]. Sclerotherapy agents like bleomycin, doxycycline and OK 432 have been used particularly in large lesions and those located in inaccessible areas [8]. Ozeki et al. have advocated the use of propranolol (a beta-blocker) as an adjunct in treating intractable lymphatic malformations [10].

A cystic mass arising in the popliteal fossa can be either a meniscal cyst, a synovial cyst (Baker's cyst) or a ganglionic cyst. 


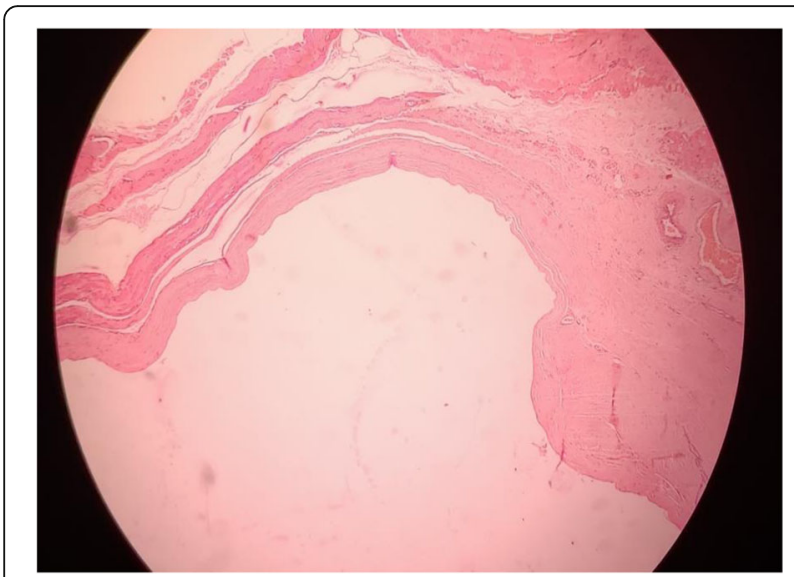

Fig. 6 Histopathology image showing multiple irregularly dilated lymphatic channels

Synovial cysts result from the extrusion of joint fluid into the gastrocnemius and the semimembranosus bursa through a weak portion of the posteromedial capsule of the knee between the medial head of the gastrocnemius muscle and the semimembranosus tendon [2]. Visualising a communicating fluid collection arising between the tendons of the medial head of the gastrocnemius and semimembranosus is the key to making a diagnosis.

Ganglionic cysts are soft tissue masses caused by the myxoid degeneration of the connective tissue at the joint capsules and tendon sheaths [11]. The ganglia demonstrate low-signal intensity on T1W images and highsignal intensity on T2W images and may show rim enhancement.

Meniscal cysts are believed to form as a result of tears in the meniscal fibrocartilage, with the extrusion of synovial fluid through the meniscal tear. Meniscal cysts have low signal intensity on T1W images and increased signal intensity on fluid sensitive sequences and may show peripheral contrast enhancement [12].

Lymphangiomas are uncommon vascular malformations with the posterior triangle of the neck being the most common site. Meniscal cyst, synovial cyst (Baker's cyst) and ganglionic cyst are common differentials for cystic lesions in the popliteal fossa. Lymphangioma should be suspected if the lesion appears multiseptated with no synovial continuity or internal derangement of the knee.

\section{Conclusion}

Lymphangioma must be included in the differential diagnosis of any cystic lesion if the lesion appears multiseptated and/or infiltrative (Table 1). At the popliteal fossa, it presents as a multiseptated cyst with no synovial continuity or internal derangement of the knee. Lymphangioma has no specific imaging features; still should be considered in the differential diagnosis if Baker's cyst is not evident.

Table 1 Differential diagnosis for cystic lesions in and around the popliteal fossa

\begin{tabular}{|c|c|c|c|c|}
\hline & Ganglion cyst & Baker's cyst & Parameniscal cyst & Lymphangioma \\
\hline $\begin{array}{l}\text { Age } \\
\text { predominance }\end{array}$ & Adults & $4-7$ years $/ 35-70$ years & Adults & Paediatric \\
\hline $\begin{array}{l}\text { Related } \\
\text { structures }\end{array}$ & $\begin{array}{l}\text { Joint-related ligament and } \\
\text { tendon }\end{array}$ & $\begin{array}{l}\text { Gastrocnemius } \\
\text { semimenbranosus bursa }\end{array}$ & $\begin{array}{l}\text { Meniscocapsular } \\
\text { junction }\end{array}$ & Intermuscular plane \\
\hline $\begin{array}{l}\text { Knee joint } \\
\text { extension/ } \\
\text { association }\end{array}$ & \pm & + & + & - \\
\hline Ultrasound & $\begin{array}{l}\text { Well-defined anechoic to } \\
\text { hypoechoic lesion with } \\
\text { few internal septae }\end{array}$ & $\begin{array}{l}\text { Well-defined anechoic cyst } \\
\text { extending to the joint } \\
\text { space. 'Speech bubble' } \\
\text { sign } \\
\text { Internal echoes can be } \\
\text { seen if infected }\end{array}$ & $\begin{array}{l}\text { Anechoic to hypoechoic } \\
\text { cyst with a tear in the } \\
\text { adjacent meniscus }\end{array}$ & $\begin{array}{l}\text { Multiloculated cystic lesion with thin septations } \\
\text { mostly anechoic but can have internal echoes } \\
\text { when associated with infection or haemorrhage }\end{array}$ \\
\hline MRI & $\begin{array}{l}\text { T1 hypointense and } \mathrm{T} 2 \\
\text { hyperintense cystic lesion } \\
\pm \text { few thin internal } \\
\text { septations } \\
+/ \text { peripheral post- } \\
\text { contrast enhancement }\end{array}$ & $\begin{array}{l}\text { T1 hypointense and T2 } \\
\text { hyperintense cystic lesion } \\
\text { extending from the joint } \\
\text { space } \\
\text { No post-contrast } \\
\text { enhancement }\end{array}$ & $\begin{array}{l}\text { T2 hyperintense cyst } \\
\text { communicating with a } \\
\text { tear in the adjacent } \\
\text { meniscus } \\
\text { No post-contrast } \\
\text { enhancement }\end{array}$ & $\begin{array}{l}\text { T1 hypointense and T2 hyperintense } \\
\text { multiloculated cystic lesion away from the joint } \\
\text { Peripheral and septal enhancement }+\end{array}$ \\
\hline Histopathology & $\begin{array}{l}\text { Thin connective tissue } \\
\text { capsule without synovial } \\
\text { lining }\end{array}$ & $\begin{array}{l}\text { Synovial tissue lining with } \\
\text { fibrous component }\end{array}$ & $\begin{array}{l}\text { Lined by synoviocytes, } \\
\text { collagen and fibroelastic } \\
\text { cartilage }\end{array}$ & Macroscopic multiseptated lymphatic spaces \\
\hline
\end{tabular}




\section{Abbreviations}

MRI: Magnetic resonance imaging; CT: Computed tomography; STIR: Short tau inversion recovery

\section{Acknowledgements}

Nil

\section{Authors' contributions}

EP contributed to the identification of the imaging findings in MRI and diagnosed the condition followed by manuscript preparation. SS contributed to the data collection including image retrieval and histopathological slides and equally participated in manuscript preparation. UA gave an expert opinion on the imaging features, discussed the differentials, and contributed to the manuscript preparation. TK confirmed the diagnosis in histopathology and contributed to the pathological part of the manuscript. RG helped in refining the manuscript and identified the findings in USG. All the authors have participated sufficiently in contributing to the content of Lymphangioma of popliteal fossa masquerading as Baker's cyst and have read and approved the final manuscript.

\section{Funding}

Nil

\section{Availability of data and materials}

Available

\section{Declarations}

\section{Ethics approval and consent to participate}

Ethical approval is not obtained, since it is a retrospective case report. Informed written consent had been obtained from the participant for participation and publication of the same as a case report.

\section{Consent for publication}

Informed written consent had been obtained from the participant for publication of the same as a case report.

\section{Competing interests}

The authors declare that they have no competing interests.

\section{Author details}

'Department of Radiodiagnosis, Sri Manakula Vinayagar Medical College and Hospital, Puducherry, India. ²Department of Pathology, Sri Manakula

Vinayagar Medical College and Hospital, Puducherry, India.

Received: 18 May 2021 Accepted: 7 June 2021

Published online: 17 June 2021

\section{References}

1. Flors L, Leiva-Salinas C, Maged I, Norton P, Matsumoto A, Alan H et al (2011) MR imaging of soft tissue vascular malformation: diagnosis, classification and therapy follow up. Radiographics. 31(5):1321-1340. https://doi.org/1 $0.1148 /$ rg.315105213

2. Bermejo A, De Bustamante T, Martinez A, Carrera R, Zabía E, Manjón P (2013) MR imaging in the evaluation of cystic-appearing soft-tissue masses of the extremities. RadioGraphics. 33(3):833-855. https://doi.org/10.1148/ rg.333115062

3. Sansone V, de Ponti A, Paluello GM, del Maschio A (1995) Popliteal cysts and associated disorders of the knee. Critical review with MR imaging. Int Orthop 19(5):275-279. https://doi.org/10.1007/BF00181107

4. Sharma M, Mallya V, Khurana N, Kumar P, Duggal R. Lymphovascular malformation- a report pf two cases. Journal of Clinical and Diagnostic Research. 2017 11(5):ED03

5. Huang J, Shin J, Huang Y, Chao C, Ho S, Wu M et al (2005) Small bowel volvulus among adults. J Gastroenterol Hepatol 20(12):1906-1912. https:// doi.org/10.1111/j.1440-1746.2005.03945.x

6. Paal E, Thompson L, Heffess C (1998) A clinicopathologic and immunohistochemical study of ten pancreatic lymphangiomas and a review of the literature. Cancer. 82(11):2150-2158. https://doi.org/10.1002/(SICI)1 097-0142(19980601)82:11<2150::AID-CNCR9>3.0.CO;2-Z
7. Abe H, Kubota K, Noie T, Bandai Y, Makuuchi M (1997) Cystic lymphangioma of the pancreas: a case report with special reference to embryological development. Am J Gastroenterol 92(9):1566-1567

8. Jain D, Selhi HS, Yamin M. Lymphangioma presenting as juxta-articular swelling in children: a case series. APSP J Case Rep. 2013;4(2):30.

9. Boc S, Panagakos P, Sadri S. Lymphangioma of the foot: a case report. The Foot and Ankle Online Journal. 2011; 4(2).

10. Ozeki M, Kanda K, Kawamoto N, Ohnishi H, Fujino A, Hirayama M, Kato Z, Azuma E, Fukao T, Kondo N (2013) Propranolol as an alternative treatment option for pediatric lymphatic malformation. Tohoku J Exp Med 229(1):6166. https://doi.org/10.1620/tjem.229.61

11. Han H, Kim J, Moon S (2015) A cystic mass in the popliteal fossa and its differential diagnosis. Arch Plast Surg 42(4):484-486. https://doi.org/10. 5999/aps.2015.42.4.484

12. Telischak NA, Wu JS, Eisenberg RL (2014) Cysts and cystic appearing lesions of the knee: a pictorial essay. Indian J Radiol Imaging 24(2):182-191. https:// doi.org/10.4103/0971-3026.134413

\section{Publisher's Note}

Springer Nature remains neutral with regard to jurisdictional claims in published maps and institutional affiliations.

\section{Submit your manuscript to a SpringerOpen ${ }^{\circ}$ journal and benefit from:}

- Convenient online submission

- Rigorous peer review

- Open access: articles freely available online

- High visibility within the field

- Retaining the copyright to your article

Submit your next manuscript at $\boldsymbol{\nabla}$ springeropen.com 